\title{
Produzir MAÇÃS, CONSTRUIR SENTIDOS: GÊNESE DA POMicultura No SUl do BRASIL ${ }^{1}$
}

\author{
Leonardo SILVA* \\ Marcia da Silva MAZON**
}

RESUMO: À luz da Sociologia Econômica, neste artigo analisamos aspectos da gênese da indústria brasileira de maçãs seguindo os passos da família Frey. Argumentamos que as atividades econômicas desenvolvidas pelos Frey contribuíram de forma determinante não apenas para a emergência do município de Fraiburgo (SC), como também para o desenvolvimento da moderna pomicultura brasileira. Longe da ideia do movimento espontâneo dos mercados, mostramos como a tomada de posição de um agente reconfigura o campo reconvertendo outros agentes e aproveitando uma janela de oportunidade da lei de incentivo ao reflorestamento que passa a fazer parte do universo dos possíveis. Seguimos a trajetória sócioprofissional de Willy Frey e apontamos sua habilidade em mobilizar uma rede de relações que lhe permitiu obter - tanto diretamente, como através de mediadores intervenções favoráveis do Estado e recursos que foram essenciais à implantação de grandes pomares em Fraiburgo e, por conseguinte, à conversão da região Sul no primeiro e principal polo produtor de maçãs do Brasil.

PALAVRAS-CHAVE: Indústria brasileira de maçãs. Agentes econômicos. Tomada de posição. Estado. Mercado.

\footnotetext{
UFSC - Universidade Federal de Santa Catarina. Programa de Pós-Graduação em Sociologia Política. Florianópolis - SC - Brasil. 88049900 - leosociais2011@hotmail.com.

"* UFSC - Universidade Federal de Santa Catarina. Programa de Pós-Graduação em Sociologia Política. Florianópolis - SC - Brasil. 88049900 - marciadasilvamazon@yahoo.com.br.

1 Este artigo é uma síntese de um dos capítulos da dissertação intitulada: $A$ gênese do valor econômico dos serviços de polinização prestados pelas abelhas à indústria de maçãs de Fraiburgo (SC): análise à luz da Nova Sociologia Econômica (NSE). Mais detalhes sobre a pesquisa e metodologia de análise ver: http://tede.ufsc.br/teses/PSOP0557-D.pdf
} 


\section{Introdução}

Porque ao subirmos a Serra Catarinense a paisagem que surge é marcada por grandes pomares de maçãs? Um especialista com pendor liberal provavelmente argumentaria que condições de clima e solo favoráveis a esse cultivo foram aproveitadas por atores racionais maximizadores de suas oportunidades. Adeptos da chamada vertente estruturalista provavelmente diriam que isto é parte inexorável do processo de penetração do capitalismo no mundo agrário introduzindo alternativas para a produção em grande escala que muitas vezes expulsam pequenos produtores. Propomos neste artigo um caminho do meio entre essas duas vertentes, uma perspectiva institucionalista apoiada na Sociologia Econômica.

Com base em uma pesquisa de cunho bibliográfico e documental descrevemos uma série de eventos históricos buscando demonstrar, entre outras coisas, a intensa interatuação - frequentemente sublinhada pelos autores ligados à Sociologia Econômica - entre os agentes econômicos, agentes estatais e agentes científicos no processo de constituição da indústria de maçãs de Fraiburgo. Mais precisamente, analisamos o processo em questão seguindo os passos da família Frey. À luz das contribuições da Sociologia Econômica, buscamos demonstrar como Willy Frey - assim como Thomas Edson no caso analisado por Granovetter \& McGuire (1998) - foi capaz de mobilizar um grande contingente institucional em torno de si o qual, por sua vez, lhe permitiu promover a evidência da alternativa da produção de maçãs em Fraiburgo e fazer dessa cidade catarinense o berço da pomicultura nacional.

O presente artigo está dividido em três seções. Na primeira, esboçamos algumas considerações sobre as contribuições da Sociologia Econômica para a compreensão da construção das indústrias. Na segunda seção, abordamos brevemente o movimento de ascensão econômica da família Frey e tecemos alguns apontamentos sobre a constituição do município de Fraiburgo com ênfase no papel desempenhado pelos agentes econômicos - em especial, pela referida família nesse processo. Tão bem como acompanhamos o processo de criação do Grupo SAFRA e de estabelecimento dos primeiros grandes pomares experimentais em Fraiburgo. Na terceira seção, analisamos a trajetória sócio profissional de Willy Frey buscando demonstrar as condições sócio econômicas e culturais de gênese de um agente econômico racional e finalizamos abordando a interatuação entre agentes econômicos, científicos e políticos no processo de formação da indústria de maçãs de Fraiburgo. 


\section{Sociologia Econômica e a construção das indústrias: algumas considerações}

Neste artigo nos baseamos na distinção feita por Fligstein (2001) entre mercados e indústrias. Como argumenta o autor, estes não podem ser considerados sinônimos, já que, "os mercados envolvem compradores e vendedores de uma mercadoria, enquanto as indústrias referem-se a produtores de mercadorias similares." (FLIGSTEIN, 2001, p. 41). No caso aqui tratado essa distinção é importante, sobretudo, porque o mercado brasileiro de maçã s ${ }^{2}$ surgiu antes da indústria de maçãs. Com efeito, até a emergência de uma indústria brasileira de maçãs a demanda do mercado interno era suprida através de importações, sobretudo da Argentina (BRANDT, 2005; FREY, 2004). No início dos anos 1960 a maçã era o segundo principal produto agrícola importado pelo Brasil, sendo responsável pelo envio de aproximadamente 100 milhões de dólares por ano ao exterior (BRANDT, 2005; FREY, 2004).

No campo da Sociologia Econômica, o estudo clássico de Granovetter \& McGuire (1998) sobre o modelo de produção de energia elétrica nos EUA fornece alguns interessantes insights à pesquisa sobre a constituição das indústrias. Posicionando-se contra a tendência dos economistas em tratar a gênese das indústrias meramente como uma questão de eficiência, nesse trabalho Granovetter \& McGuire (1998) demonstram que o resultado da luta entre o modelo de geração de energia centralizado (baseado em grandes centrais elétricas) proposto por Thomas Edson e o modelo descentralizado (baseado em geradores individuais) proposto pelo banqueiro J.P. Morgan não foi o produto de uma equação benthamista ou de uma racionalidade otimizadora, mas sim, de parcerias antigas, experiências similares, dependências comuns, conexões corporativas e ativa criação de novas relações sociais. Como argumentam Granovetter \& McGuire (1998), as redes de relações pessoais e de negócios mobilizadas pelo secretário e braço direito de Edson, Samuel Insull, foram essenciais para que o modelo das grandes centrais elétricas saísse vitorioso deste embate. Inspirando-se no clássico estudo sobre o teclado QWERTY e o lock-in de tecnologias ineficientes, Granovetter \& McGuire (1998) argumentam que uma vez que novas formas institucionais - assim como a indústria elétrica centralizada - são

\footnotetext{
2 Esse mercado não existia da forma como o conhecemos hoje, já que, o crescimento da oferta de maçãs nacionais (mais baratas do que as importadas) gerado pelo surgimento de uma indústria da pomicultura no país sem dúvida contribuiu para alavancar a demanda. Como demonstram os dados disponíveis, enquanto em 1960 a produção brasileira de maçãs foi de 9.513 toneladas e o consumo per capita de $0,65 \mathrm{~kg}$ por habitante, em 1979 a produção foi de 37.850 toneladas e o consumo per capita de 1,90kg por habitante (KREUZ et al., 1986; KLANOVICS, 2007). O caso do mercado e da indústria de maçãs no Brasil corrobora, desse modo, a hipótese bourdieusiana de que a "[...] demanda [por um bem] se especifica e se define completamente apenas em relação a um estado particular da oferta [...]". (BOURDIEU, 2005, p. 18).
} 
criadas, elas tendem não apenas a modificar o ambiente social externo para que ele seja compatível com suas necessidades, mas também a excluir possibilidades que num momento anterior haviam se mostrado inteiramente plausíveis (nesse caso, o modelo descentralizado de geração de energia elétrica). O modelo de instituição vencedor não é, portanto, o mais eficiente e sim aquele bem sucedido num processo político-cultural passível de contestações (BOURDIEU, 2005).

Contudo, a Sociologia Econômica não demonstra apenas que "os processos políticos que geram regras refletem frequentemente os interesses organizados de um dado conjunto de empresas num mercado [ou indústria]" (FLIGSTEIN, 2001, p. 34), mas também que dentre "todas as trocas com o exterior do campo [econômico], as mais importantes são as que se estabelecem com o Estado" (BOURDIEU, 2001, p. 253). Como Bourdieu $(2001,2005)$ argumenta em sua análise sobre a disputa entre os modelos coletivo e individual de habitação na França, em razão da capacidade do aparato estatal de contribuir para a estruturação do campo econômico, "a competição entre as empresas assume muitas vezes a forma de uma competição pelo poder sobre o poder do Estado, - nomeadamente, sobre o poder de regulamentação e sobre os direitos de propriedade - e pelas vantagens asseguradas pelas diferentes intervenções estatais" (BOURDIEU, 2001, p. 253).

Conectando leituras mais focadas nas redes de relações pessoais como a de Granovetter \& McGuire (1998) e leituras mais focadas no Estado como a de Bourdieu $(2001,2005)$, a Sociologia Econômica permite compreender que um dos modos como os agentes econômicos condicionam o Estado a executar as políticas que lhe são favoráveis é por meio dos agentes intermediários que Aldrich (2005) chama de brokers. Os brokers são via de regra pessoas de posição elevada que lançam mão de seus recursos sociais, poder e/ou prestígio para criar ligações onde o empreendedor não possui laços diretos. Nos âmbitos onde não existem conexões diretas entre o Estado e o campo econômico - isto é, onde existem os chamados buracos estruturais -, a ação dos brokers pode muitas vezes contribuir para a redução das incertezas e/ou custos envolvidos nas transações (ALDRICH, 2005).

Por fim, a Sociologia Econômica fornece uma leitura bastante fecunda acerca do comportamento dos agentes econômicos. Indo contra a pressuposição da economia neoclássica de que as convicções e preferências individuais são dadas e fixadas exogenamente, ou seja, de que dependem de uma natureza humana universalmente compartilhada e estável no tempo, autores como Bourdieu (2001, 2005) e Fligstein (2001) enfatizam a dimensão cognitiva das instituições ao argumentarem que elas não apenas regulamentam as atividades mercantis e os conflitos de interesses delas derivados, como também são responsáveis pela própria definição das disposições, interesses e estratégias dos agentes. Desse modo, a Sociologia Econômica permite compreender, por um lado, que a razão calculadora 
e maximizadora é um patrimônio histórico-cultural das sociedades capitalistas e, por outro, que mesmo em tais sociedades “[...] há condições econômicas e culturais de acesso às condutas que [a economia neoclássica] considera como racionais [...]". (BOURDIEU, 2005, p. 19). Além disso, a Sociologia Econômica demonstra que mesmo nos âmbitos onde a teoria econômica pressupõe que a racionalidade maximizadora se faz absolutamente dominante - assim como na bolsa de valores, por exemplo - dificilmente o pressuposto neoclássico da informação perfeita se concretiza efetivamente, de modo que mesmo os agentes mais racionais "habitam [sempre] um mundo obscuro em que nunca está [totalmente] claro quais ações terão quais consequências" (FLIGSTEIN, 2001, p. 31).

\section{A ascensão econômica dos irmãos Frey e o mito do empreen- dedor pioneiro}

Com o término da Primeira Guerra Mundial na Europa, a família Frey decidiu se mudar da região da Alsácia - que já havia pertencido tanto à França como à Alemanha - para o Brasil. No ano de 1919, os Frey chegaram ao país instalando-se inicialmente no município de Triunfo no Rio Grande do Sul onde permaneceram por cerca de quatro anos. Em 1923 eles se mudaram para o município de Castro no Paraná. Nessa cidade René (então com 19 anos) e Arnoldo (com 15 anos) adquiriram seus primeiros empregos em um açougue, onde aprenderam "[...] o ramo de preparo de salames e friambreria" (BURKE, 1994, p. 15).

Condicionado pela intensa publicidade que se fazia no início da década de 1930 sobre as oportunidades de enriquecimento pessoal que a recente colonização da região vale do Rio do Peixe, em Santa Catarina, havia aberto, "René Frey se entusiasmou com a ideia de abrir açougue próprio na então incipiente Perdizes (hoje cidade de Videira)" (FREY, 2005, p. 31). Já casado, René Frey se estabeleceu com sua família nessa localidade e foi seguido, alguns meses depois, por seu irmão Arnoldo Frey. Este último foi à região com o intuito de tornar-se sócio no açougue. $\mathrm{O}$ açougue - nomeado de René Frey \& Irmão Ltda. - alcançou grande êxito passando em pouco tempo a incluir também uma fábrica de derivados de carne.

Em meados da década de 1930, os irmãos Frey buscaram diversificar ainda mais seus empreendimentos empresariais e acabaram percebendo que "na região, havia madeira em abundância e a maior parte dos proprietários das terras e florestas tinha as árvores, mas lhes faltavam capital e iniciativa para extração da madeira, sua comercialização e seu aproveitamento industrial" (FREY, 2005, p. 52). A modalidade contratual proposta por René e Arnoldo Frey aos proprietários das florestas era serrar a madeira à meia, isto é, dividindo-se os lucros obtidos em $50 \%$ para os donos da 
propriedade e 50\% extratores da madeira (BURKE, 1994; FREY, 2005). Assim, em 1935 os irmãos Frey instalaram sua primeira serraria na localidade chamada Anta Gorda para serrarem às meias o pinheiral situado na propriedade de Possanski e obtiveram resultados econômicos altamente positivos (FREY, 2005). Em 1937 eles instalaram uma serraria em Rio das Pedras para explorarem as florestas existentes nas terras de Carlos Putkamer e Ermínia Ribeiro (FREY, 2005).

Seguindo a tendência que deu origem ao chamado ciclo da madeira ${ }^{3}$, em 1939 os irmãos Frey optaram por direcionar seus investimentos principalmente para o setor madeireiro (FREY, 2005). Contudo, em razão da exploração desenfreada das matas nativas pelas diversas madeireiras da região, os irmãos Frey decidiram deslocar suas atividades madeireiras instalando uma nova serraria numa região pouco explorada repleta de pinheirais denominada Campo da Dúvida (BURKE, 1994; FREY, 2005). Essa área de 5.000 hectares coberta de pinheiros era de propriedade da família Ramos de Lages, que na época já detinha grande poder político e econômico. Por meio do estabelecimento com os Ramos de um acordo de serrar às meias, os irmãos Frey instalaram uma serraria de grande porte em Campo da Dúvida. Os lucros gerados pela serraria permitiram aos irmãos Frey estabelecerem na região de Butiá Verde, um açougue, um armazém, uma escola e um salão para a realização de reuniões, bailes e manifestações artísticas (BURKE, 1994; FREY, 2005).

A partir da análise dos relatos sobre a história empresarial de sucesso dos irmãos Frey, observa-se que os autores Willy Frey (2005) e Ary Nogueira da Silva (2006) mobilizam constantemente àquilo que Bourdieu (2014) chamou de estratégias de sociodiceia ${ }^{4}$. Estes biógrafos atribuem certos talentos empresariais inatos - como a aptidão ao trabalho duro, o dinamismo, a austeridade, a atitude, o pragmatismo, o arrojo, etc. - aos irmãos Frey; talentos estes que são apresentados como o fundamento central do sucesso econômico destes agentes. Do mesmo modo, as habilidades mercantis dos Frey igualmente surgem associadas à origem europeia não-lusa. Em certos trechos, os biógrafos referem-se, por exemplo, à disciplina rígida e à severidade germânica de René Frey e lembram como ele era conhecido por exigir de seus empregados uma conduta irrepreensível no trabalho.

\footnotetext{
3 A partir nomeadamente de 1920, a madeira tornou-se alvo de um processo de valorização "[...] em relação ao campo [que servia de pastagem], até então de principal interesse, despertando a cobiça de muitos grupos políticos e econômicos [...]" (BRANDT, 2007, p. 237) os quais, por sua vez, decidiram então dedicarem-se à exploração madeireira. Este intenso movimento de exploração das reservas florestais, que se prolongou até mais ou menos à década de 1960 ficou conhecido como ciclo da madeira (BRANDT, 2007).

4 Sociodiceia é um termo que foi forjado por Bourdieu (2014, p. 319) "[...] a partir do modelo da palavra de Leibniz, a teodiceia, que é justificação de Deus; a sociodiceia é a justificação da sociedade [ou de alguma parte dela]. Essa noção designa estratégias que tem como função justificar as coisas pelo fato de serem o que são."
} 
Por outro lado, tais biógrafos igualmente sublinham que René era sensível aos problemas pessoais de seus empregados e que muitas vezes participava ativamente nas soluções dos mesmos (SILVA, 2006). Sobre este ponto, Willy Frey (2005, p. 86) afirma que a tenacidade "[...] com que demandavam ampliação de seus empreendimentos era sempre também direcionada para a solução de problemas de ordem social e comunitária, envolvendo melhoria de vida para todos aqueles, que, de alguma forma, lhes prestavam serviços." E mais adiante ele reconhece: "Indubitavelmente, esse modo de agir em muito contribuiu para a solidificação de seus empreendimentos porquanto existia um engajamento solidário de todos os empregados, nas atividades das empresas." (FREY, 2005, p. 86). Ao que tudo indica, temos aqui um exemplo de um agente econômico que possui certas disposições e estratégias que são típicas ao patriarca patrimonial weberiano ou, o que seria provavelmente mais preciso, que deve parte da eficácia de sua dominação econômica ao seu capital simbólico. Por sua vez, tal capital simbólico tende a ser acumulado notadamente por meio da distribuição de benefícios e dons aos agentes submetidos à dominação econômica. Como argumenta Weber (2012, p. 321), "[...] o patrimonialismo patriarcal tem que legitimar-se diante de si mesmo e dos súditos como protetor do bem-estar destes últimos." Contudo, o patrimonialismo patriarcal não surge "[...] da livre camaradagem baseada no juramento de fidelidade, mas sim de um relação autoritária entre pai e filhos: o "pai do povo" [...]." (WEBER, 2012, p. 321).

Uma consequência dessa relação de dominação econômica parcialmente fundada em certos aspectos do patrimonialismo patriarcal, é a tendência que os biógrafos supracitados tiveram ao colocar em grande destaque, não apenas os talentos empresariais supostamente inatos, mas também os grandes benefícios socioeconômicos que os empreendimentos empresariais dos irmãos Frey teriam trazido para a região do Vale do Rio do Peixe, de um modo geral, e para a cidade de Fraiburgo, em particular. Para tanto, tais autores tendem a acionar, conforme propõe Renk (1998), estratégias representacionais tais como construtores do progresso, missão civilizadora, as quais acabaram por fazer do enriquecimento pessoal e familiar dos Frey não apenas um fato moralmente aceito como também benéfico para o restante da sociedade. Os Frey teriam civilizado uma região inóspita, transformado uma terra erma e reconhecidamente violenta em um centro gerador de empregos, renda e progresso. É nesse sentido, por exemplo, que o ex-funcionário Irineu Secchi (2005, p. 8), por ocasião da homenagem prestada ao centenário do nascimento de René Frey, afirma: “Acima de seus interesses e negócios pessoais, [René] colocava a preocupação com o desenvolvimento de sua cidade de Fraiburgo, e o bem-estar da população."

Nesse ponto, os biógrafos e outros agentes de celebração deixam logicamente de mencionar, entre outras coisas, que antes da chegada das correntes de 
colonizadores europeus não-lusos já haviam habitantes instalados nessa região há mais de uma geração (RENK, 1998; BRANDT, 2007). Contudo, como fica claro a partir de análises como a de Renk (1998), estes habitantes (geralmente chamados de caboclos ou brasileiros) estavam longe de possuir as disposições, capitais, estratégias, interesses e tomadas de posições que se adequassem ao projeto de modernização estabelecido pelos dirigentes do Estado brasileiro.

\subsection{A constituição do município de Fraiburgo: a contribuição dos agentes econômicos para a gênese de uma unidade política}

No ano de 1958 a empresa René Frey e Irmão Ltda., já bastante diversificada em seus empreendimentos mercantis, era composta por duas grandes serrarias, um potente moinho, fábrica de caixas, fábrica de crina vegetal, cantina vinífera, açougue com matadouro próprio, granja de suínos, olaria e fábrica de pasta mecânica. Nesse período havia se instalado outras serrarias na região o que atraiu muitos trabalhadores, gerou lucros e levou à rápida extinção das matas nativas.

Com a chegada, em janeiro de 1959, de João Marques Vieira para ocupar o cargo de diretor contábil da empresa dos irmãos Frey, surgiu a ideia "[...] de [...] substituir o nome [Butiá Verde] por outro mais prático e adequado." (BURKE, 1994, p. 24). Ao perceber que as pessoas da região ao se referirem "[...] ao povoado nem sequer mencionavam mais o nome Butiá Verde, apenas Frey (pronunciase Frai).”, João Marques “[...] não teve dúvidas em sugerir a mudança [...] para Fraiburgo: a "Vila dos Frey." (BURKE, 1994, p. 24). Após recolher as assinaturas dos moradores, Marques encaminhou uma petição à Prefeitura de Curitibanos que rapidamente aprovou a mudança do nome da vila de Butiá Verde para Fraiburgo (BURKE, 1994).

Com o intuito de transformar a vila operária de Fraiburgo em uma cidade planejada, em 1959 o filho de René, Willy Frey, em parceria com o grupo empresarial René Frey e Irmão Ltda., iniciou um projeto de urbanização na região (SILVA, 2006). Após vender rapidamente aos operários as casas em que residiam e mais alguns terrenos, Willy Frey decidiu encomendar no Rio de Janeiro um plano urbanístico para a futura cidade (BURKE, 1994; FREY, 2005; SILVA, 2006).

\footnotetext{
5 Indo contra a visão autóctone de que a alteração do nome de Butiá Verde para Fraiburgo deveu-se apenas à uma busca por maior praticidade e adequação à linguagem popular, Klanovicz \& Nodari (2005, p. 36) propõem que "[...] a principal motivação com relação à mudança do nome da localidade residia na implementação do discurso modernizador, por meio da utilização de um nome que se assemelhava ao progresso, um nome "estrangeiro" e que remetia, simbolicamente, a uma "europeização", em detrimento de um nome indígena, Butiá. A palavra burgo remetia à noção de cidade permanente, oficial, sólida, espaço da burocracia, das leis, da burguesia, da ordem, espaço no qual se engendra a civilização."
} 
De acordo com Burke (1994, p. 25), devido ao “[...] grande desenvolvimento da economia privada e [à] expansão do setor comercial, Fraiburgo tornou-se o maior contribuinte do Município de Curitibanos, o que levou a população, em 1960, a começar a sonhar com sua emancipação." Aos poucos tal ideia tomou vulto e em janeiro de 1961 foi eleita Comissão Pró-criação do Município de Fraiburgo, a qual tinha René Frey como presidente (BURKE, 1994; FREY, 2005). Até o fim deste ano foram travadas "[...] lutas nos bastidores da política [catarinense]. A 16 de dezembro, René [Frey] dirigiu-se a Florianópolis para promover gestões junto aos Deputados, na Assembleia Legislativa do Estado." (FREY, 2005, p. 96). Tal conflito se deu porque os propositores do projeto de emancipação de Fraiburgo tiveram que vencer "[...] a oposição daqueles que eram contra a ideia, especialmente os representantes de Curitibanos, que não queriam perder uma parte importante do seu Município e seu maior contribuinte [...]." (BURKE, 1994, p. 26). Nesse sentido, Willy Frey (2005, p. 96) argumenta que o “[...] relacionamento [de seu pai René Frey] com personalidades políticas do Estado e da cidade de Curitibanos, a cujo município estava integrada Butiá Verde, foram fatores preponderantes para a concretização do projeto [de emancipação de Fraiburgo]." Assim, no dia 20 de dezembro de 1961 foi aprovada pela Assembleia Legislativa do Estado de Santa Catarina, através da Lei Estadual n 797, a criação do município de Fraiburgo (BURKE, 1994; FREY, 2005). Em 31 de dezembro de 1961 foi oficialmente instalado, em meio a grandes festejos públicos, o município de Fraiburgo.

Com base nessa breve descrição do processo de instituição do município de Fraiburgo pode-se perceber como o inter-relacionamento que se estabelece entre o Estado e o campo econômico (e os diferentes agentes que o compõem) está longe de ser uma via de mão única. Não é apenas, como corretamente se tem insistido no âmbito da Sociologia Econômica contemporânea, o Estado que ao se construir contribui para a formação da esfera econômica, mas também, a esfera econômica que ao se construir contribui para a criação do Estado. Com efeito, a história da constituição do município de Fraiburgo demonstra como a emergência de indústrias e de um mercado consumidor em uma região anteriormente desabitada pode conduzir à criação de uma nova unidade política (nesse caso uma cidade).

Essa constatação, apesar de algumas vezes esquecida não é, contudo, nova. Weber (2012) já havia proposto que alguns tipos de mercados podem transformar o lugar em que se realizam em cidades. Em sua tipologia das cidades, ele argumenta que dois fatores são fundamentais à emergência de uma cidade: (1) "a existência de uma [...] sede principesca [i.e., de uma "sede de autoridades estatais"], como centro, para cujas necessidades econômicas ou políticas trabalham [em parte] as indústrias, com especialização da produção, e o comércio adquire bens." e; (2) "a realização de uma troca de bens não apenas ocasional mas regular, na localidade, como 
componente essencial das atividades aquisitivas e da satisfação das necessidades dos moradores: a existência de um mercado." (WEBER, 2012, p. 409). No caso específico de Fraiburgo pode-se notar como o surgimento do mercado (ou, mais especificamente, do mercado consumidor local e das indústrias locais) não é apenas anterior à instituição de uma sede de autoridades estatais (ou, mais especificamente, de unidade político-administrativa autocéfala) na localidade, como ainda é um elemento fundamental no processo de emancipação política da mesma. Isso, não apenas porque Fraiburgo nasceu de uma vila construída pela empresa René Frey \& Irmão Ltda. para abrigar seus trabalhadores, a instituição do próprio município foi produto da luta dos empresários locais organizados em torno da Comissão Prócriação do Município de Fraiburgo.

\subsection{O Grupo SAFRA e os primeiros pomares experimentais em Fraiburgo}

Devido ao declínio das reservas de madeira causado pela extração continuada, Arnoldo e René Frey decidiram entrar, já na década de 1950, no ramo da fruticultura por meio do cultivo de ameixas destinadas à comercialização in natura e de uvas destinadas nomeadamente à produção de vinhos (SCHMIDT, 1990; BRANDT, 2005). Contudo, como faltava aos irmãos Frey recursos econômicos, tecnológicos e humanos suficientes para deslancharem seu novo empreendimento empresarial, eles começaram a procurar por possíveis sócios (BRANDT, 2005). Por meio de sua rede de relações pessoais, Willy Frey acabou conhecendo os empresários franco-argelinos Gabriel e seu filho Henri Evrard que devido ao processo de independência da Argélia vieram ao Brasil à procura de novas oportunidades de investimento no setor vinícola (SCHMIDT, 1990; SILVA, 2004; BRANDT, 2005). Com a proclamação da independência da Argélia em 1962, a família Evrard se dirigiu para o município de Fraiburgo com a família francesa Mahler à qual era associada. Juntamente com René e Arnoldo Frey as famílias Evrard e Mahler fundaram em março desse mesmo ano a Sociedade Agrícola Fraiburgo Ltda. (SAFRA) (BURKE, 1994; PETRI et al., 2011). Para a criação desta nova empresa os irmãos Frey entraram com 1.000 hectares de terra que possuíam na região de Fraiburgo onde já se encontravam alguns parreirais de uvas, um pomar de ameixas e uma cantina na qual o vinho era fabricado, enquanto que o grupo Evrard-Mahler entrou com o capital necessário para a expansão da produção de uvas e para modernização da cantina, sendo que à cada família associada coube 33\% do capital (SCHMIDT, 1990; BRANDT, 2005).

Buscando expandir ainda mais seus experimentos com a fruticultura de clima temperado em Fraiburgo, nos anos de 1963 e 1964 o grupo SAFRA realizou duas 
grandes importações de porta-enxertos e mudas de árvores frutíferas da França (destaque para as macieiras) (BURKE, 1994; FREY, 2004). Essas importações tornaram possível o maior e mais diversificado viveiro experimental de fruteiras de clima temperado do Brasil no período. Segundo Willy Frey (2004), no ano de 1967 as pesquisas realizadas pelo SAFRA já concluíam que o cultivo de macieiras era a opção mais rentável economicamente. Com base nesses resultados preliminares e no fato que a maior parte das maçãs consumidas no Brasil na época eram importadas, o grupo SAFRA decidiu iniciar imediatamente tanto a produção e comercialização de mudas de macieiras em escala comercial como o plantio de seus primeiros pomares próprios (FREY, 2004).

Contudo, não obstante a moderna pomicultura nacional ter início com as atividades pioneiras do grupo SAFRA, o cultivo de grandes pomares de macieiras somente ganhou impulso com a criação da empresa Reflorestamento Fraiburgo Ltda. (REFLOR) por Willy Frey no ano de 1967 (FREY, 2004; SILVA, 2006). Com efeito, Willy Frey foi o empresário brasileiro responsável tanto pela introdução das macieiras no âmbito das árvores frutíferas citadas pela legislação que regulava o uso de incentivos fiscais concedidos pelo governo militar a partir da década de 1960 para a realização de florestamentos, como pelo cultivo e administração dos primeiros grandes pomares de macieiras plantados com tais incentivos no país (BURKE, 1994, FREY, 2004; SILVA, 2006). Tendo-se em vista esse papel fundamental desempenhado por Willy Frey no processo de constituição da indústria brasileira de maçãs na seção seguinte abordamos em maiores detalhes a sua trajetória sócio profissional.

\section{Willy Frey: as condições sócio econômicas e culturais de gênese de um agente econômico racional}

Silva (2006) relata, em seu livro Trajetória de um empreendedor ${ }^{6}$, que em suas iniciativas econômicas Willy Frey sempre buscou implementar um modo de gestão metódico e racional baseado em cálculos precisos para aferição de custos e lucros. De acordo com Silva (2006), Willy Frey teria buscado convencer os irmãos Frey a substituírem o modo de gestão predominantemente empírico utilizado por eles em

\footnotetext{
6 Não obstante o caráter profundamente celebrativo e apologético deste livro - o qual foi produzido como uma homenagem a Willy Frey - ele sem dúvida traz uma série de informações importantes sobre a trajetória sócio profissional de Willy Frey. Além disso, como demonstram sobretudo os autores ligados à Sociologia das elites, a própria natureza das fontes disponíveis sobre um dado agente ou grupo de elite traz à tona certas propriedades que podem ser essenciais aos mesmos. Como argumenta Miceli (2001, p. 349), "[...] as fontes impressas e aquelas manuscritas (materiais constantes de arquivos históricos e familiares) retêm a marca dos interesses, dos valores e das estratégias dos grupos sociais a que se referem."
} 
suas empresas, por métodos mais racionais de administração e contabilidade, os quais permitiriam, por sua vez, "[...] descobrir pontos de estrangulamento e calcular custos com rigor absoluto." (SILVA, 2006, p. 34). Porém, não obstante os relatórios repletos de cálculos demonstrativos elaborados por Willy Frey, nas firmas de sua família, "[...] suas ideias inovadoras eram recebidas com reserva até mesmo por parte de colaboradores mais antigos, com base no raciocínio simplista de que, "se havia lucro, nada precisava ser mudado"." (SILVA, 2006, p. 35). Pode-se perceber, desse modo, certo descompasso entre as disposições e estratégias econômicas dos irmãos Frey - pautadas predominantemente por aquilo que Weber (2012) chamou de racionalidade (econômica) material - e as disposições e estratégias econômicas de Willy Frey - pautadas nomeadamente em uma racionalidade (econômica) formal. Enquanto o primeiro tipo-ideal de racionalidade econômica envolve considerações valorativas do gênero se há lucro, nada precisa ser mudado, o segundo tende a ser pautado sobretudo pelas prerrogativas técnico-financeiras de progressiva (e teoricamente infinita) minimização dos custos e maximização dos lucros.

Assim, poder-se-ia sugerir que Willy Frey personifica, em certo sentido e até certo ponto, o ator economicamente racional - homo economicus - que tende a ser tido como um pressuposto, como um dado, pela teoria econômica neoclássica. Contudo, as disposições, interesses, estratégias e tomadas de posição economicamente racionais de Willy Frey estão longe de ser inatas ou universais. Como demonstra Bourdieu (2005, p. 23), as aptidões ao trabalho, ao cálculo, ao investimento, à poupança, etc. "[...] não são exógenas, isto é, dependentes de uma natureza humana universal [ou mesmo de um talento individual inato], mas endógenas e dependentes de uma história [...]." Consequentemente, mesmo um agente economicamente racional é necessariamente um constructo sócio histórico do qual apenas uma análise genética pode dar conta. Nesse sentido, o mapeamento da trajetória sócio profissional de sucesso de Willy Frey demonstrou que este agente: (1) passou sua infância em comunidades pequenas e relativamente pouco diferenciadas; (2) foi exposto à disciplina rígida e à severidade germânica de seu pai René; (3) estudou durante anos num internato católico (Maristas) e numa escola protestante de elite (Mackenzie); (4) teve uma socialização precoce e continuada no mundo do negócios e; (5) formou-se em áreas que preparam para a atuação no campo econômico como contabilidade e administração (SILVA, 2006).

Como Lahire (2002) permite compreender, a vida em sociedades tradicionais e a passagem pelo regime de internato estão dentre as situações históricas que contribuem para a constituição de um sistema de disposições homogêneo, durável e

7 Como argumenta Bourdieu (2001, p. 271), “[...] os diferentes membros da direção [tendem a ter] sobre a empresa, e sobretudo sobre seu futuro, pontos de vista que [dependem] estreitamente da sua posição na empresa e do seu capital escolar." 
transponível. Grün (2003, p. 67), por seu turno, demonstra que "[...] a escolarização realizada em instituições privadas [de elite], como a Mackenzie, [tem] a grande virtude de parecer diminuir o ardor corporativo que as profissões universitárias tradicionais costumam produzir em seus seguidores, não deixando embotar o tino comercial.", enquanto que Nogueira (2003, p. 56) demonstra que "a concepção de que a formação para o empreendedorismo deve começar cedo [e muitas vezes ocupando funções subalternas nos negócios familiares] parece ser [bastante] comum no meio empresarial."

Além de poder ser inferido, com base nas características de sua trajetória sócio profissional, o caráter significativamente homogêneo e racionalmente orientado do sistema de disposições de Willy Frey e também constatado empiricamente a partir, por exemplo, da homologia entre as suas tomadas de posição no campo econômico e no campo político. Conforme indicam os dados disponíveis, quando foi prefeito de Fraiburgo em 1973 Willy aplicou os mesmos princípios racionais de gestão econômica que utilizava em suas empresas. Entre outras coisas, ele tabulava e analisava cuidadosamente as sugestões da população para um eventual aproveitamento administrativo e publicava todo mês uma Carta Circular na qual apresentava aos cidadãos um balanço financeiro das receitas e despesas do município - numa clara analogia com o modo como são geridas as sociedades por ações na economia capitalista (SILVA, 2006).

\subsection{Agentes e ações na formação da indústria de maçãs de Fraiburgo}

Sabe-se que no início da década 1960 o Estado brasileiro tinha certa preocupação com os gastos crescentes relacionados ao aumento das importações de maçãs, que era o segundo produto agrícola mais importado pelo Brasil, ficando atrás apenas do trigo (BRANDT, 2005). Contudo, apesar dessa preocupação com a perda de divisas, nesse período o poder estatal ainda não havia tomado nenhuma iniciativa concreta objetivando superar as dificuldades técnicas associadas ao cultivo de maçãs (uma fruta de clima temperado) no Brasil (um país predominantemente tropical).

Esse quadro começa a mudar, sobretudo, a partir de meados de 1960 quando a família Evrard solicitou ao francês Georges Delbard, então maior viveirista e especialista em fruticultura da Europa, que prestasse consultoria aos pomares do grupo SAFRA em Fraiburgo (SCHMIDT, 1990). Ao inspecionar tais pomares, Delbard chegou à conclusão de que "[...] era possível cultivar com sucesso (ou lucro) árvores frutíferas dos países temperados no Sul do Brasil nas altitudes acima de 1.000 metros." (SCHMIDT, 1990, p. 68). Buscado transmitir suas impressões às autoridades brasileiras e assim angariar seu apoio Delbard, agora associado ao 
grupo SAFRA, voltou a Paris e contatou o Ministro de Comércio Exterior da França, Charles de Chambrum, e conseguiu que ele fosse oficialmente convidado para vir ao Brasil (SCHMIDT, 1990). Assim, no início de 1967 Delbard expôs seu parecer sobre a possibilidade de se produzir maçãs em escala comercial no Sul do país ao Ministro do Planejamento Roberto Campos e ao Ministro do Comércio Exterior Vilar Queiroz (SCHMIDT, 1990).

Para fazer com que a questão da produção de maçãs adquirisse maior ressonância em diferentes instituições públicas e privadas, tais como ministérios, bancos, associações profissionais, etc., Delbard apresentou em março de 1967 um projeto-modelo integrado de fruticultura para o Brasil nomeado "Produção Industrial Brasileira de Frutas de Clima Temperado" (SCHMIDT, 1990). Como demonstrou Schmidt (1990), todo esse esforço feito de Delbard para impulsionar o desenvolvimento da pomicultura no Brasil estava diretamente ligado aos interesses do grupo SAFRA em converter-se em um grande fornecedor de mudas.

Além de convencer autoridades estatais e privadas brasileiras quanto à possibilidade de se produzir com êxito maçãs no país, Delbard e o grupo SAFRA igualmente se aproximaram dos produtores agrícolas. Juntamente com Willy Frey, que lhe servia de intérprete, Delbard percorreu "[...] toda a região Sul do país [...], fazendo reuniões com proprietários rurais e incentivando-os ao plantio de macieiras. Ensinava que a cultura da macieira é uma das mais rentáveis atividades agrícolas." (FREY, 2004, p. 29).

Nesse período, as áreas cultivadas com macieiras em Santa Catarina ainda se restringiam, em grande medida, ao pomar experimental da SAFRA em Fraiburgo e ao pomar de Rogério Campos em São Joaquim (SCHMIDT, 1990). Com efeito, seria apenas com a inclusão das macieiras na chamada lei federal dos incentivos fiscais ao florestamento e reflorestamento, que o processo de constituição da indústria brasileira adquiriu o impulso de que precisava para lhe conduzir a um novo estágio.

\subsection{Maçãs e a constituição do ambiente legal}

Promulgada no dia 2 de setembro de 1966 pelo governo do General Castello Branco, a lei $\mathrm{n}^{\circ} 5.106$ estabelecia que as pessoas jurídicas poderiam “[...] descontar do imposto de renda que devam pagar, até $50 \%$ do valor do imposto, as importâncias comprovadamente aplicadas em florestamento ou reflorestamento, que poderá ser feito com essências florestais, árvores frutíferas [...]." (BRASIL, 1966, p. 1). Enquanto despesas de florestamento e reflorestamento, essa legislação compreendia as importâncias investidas diretamente pelo contribuinte ou "[...] mediante a contratação de serviços de terceiros [...].” (BRASIL, 1966, p. 1). 
Contudo, apesar de abrir tanto a possibilidade de se utilizar incentivos fiscais para florestar e reflorestar com árvores frutíferas", quanto a possibilidade de se criar uma prestadora de serviços para realizar tais florestamentos e reflorestamentos, essa lei não especificava quais árvores frutíferas poderiam ser cultivadas. Coube a Willy Frey ter a ideia e tomar a iniciativa de tentar incluir efetivamente a macieira no âmbito do conceito de árvores frutíferas utilizado pela legislação instituída pelo governo militar.

No início de 1967 Willy Frey, que desde a instituição da lei n 5.106 observava seus desdobramentos, decidiu retornar ao município de Fraiburgo e fundar a empresa Reflorestamento Fraiburgo Ltda. (REFLOR). Na prática, a REFLOR seria utilizada como plataforma para a captar recursos de incentivos fiscais do imposto de renda junto às grandes empresas comerciais e industriais para serem aplicados em reflorestamentos, inicialmente de pinus e depois de macieiras. Restava, contudo, convencer os empresários da rentabilidade do investimento em reflorestamento. Nessa época, porém, prevalecia o desconhecimento e, em alguns casos, a desconfiança por parte do empresariado brasileiro com relação aos incentivos fiscais concedidos pelo Estado, fato que levou Willy a buscar a orientação da empresa de publicidade carioca Abaeté Propaganda (FREY, 2003). Assim, Willy passou a mobilizar o recurso audiovisual com projeção de slides (uma novidade na época) nas suas palestras e reestruturou sua proposta inicial de adesão aos projetos de reflorestamento alicerçando-a tanto na confiança aos nomes da empresa reflorestadora e de seu responsável ${ }^{8}$ quanto na comprovada rentabilidade e bons resultados econômicos do empreendimento ${ }^{9}$ (FREY, 2003). Ainda no ano de 1967, Willy teve a oportunidade de proferir uma palestra durante o encontro empresarial promovido pela Associação Comercial de Joinville, a qual se mostrou decisiva para estabelecer a confiança no projeto e atrair investidores (SILVA, 2006).

Assim, após obter os recursos financeiros necessários, a recém fundada REFLOR de Willy Frey iniciou suas atividades reflorestando áreas do município de Fraiburgo com pinus. Concomitantemente a isso, Willy passou a realizar pressões junto ao Instituto Brasileiro do Desenvolvimento Florestal (IBDF) visando obter a extensão do benefício federal também à cultura da macieira. De acordo com ele houve, no entanto, certa resistência inicial por parte da burocracia do IBDF em

\footnotetext{
8 Segundo o próprio Willy (2003), esse nome de confiança Ihe era dado pela "Família Frey, "[...] dos irmãos fundadores de Fraiburgo e empreendedores tradicionais na região [...]." Como pode-se perceber, Willy tem certa consciência de que o prestígio do sobrenome Frey pode lhe servir como um trunfo no campo econômico. Por sua vez, à luz da sociologia bourdieusiana, poder-se-ia argumentar que este prestígio nada mais é do que o capital simbólico acumulado pelos irmãos René e Arnoldo Frey em sua trajetória de progressiva ascensão econômica.

9 O argumento principal nesse ponto era de que caso "[...] não fosse aplicados em reflorestamento os valores da dedução permitida integrariam o total de imposto de renda a ser recolhido pelo fisco. E sem retorno às empresas." (FREY, 2003, p. 49-50).
} 
aceitar a inclusão da macieira na lei dos incentivos fiscais (FREY, 2003). Segundo Willy, para tais funcionários prevalecia a perspectiva de que o deferimento de tal proposta abriria precedente "[...] para o ingresso de pedidos assemelhados, sobretudo possivelmente provenientes do nordeste do país, para estender a aplicação dos incentivos fiscais a outros cultivos de árvores frutíferas, como de goiabeiras, mangueiras e até de bananeiras, etc." (FREY, 2003, p. 56). De modo a superar tais resistências, Willy Frey - mobilizando seu significativo capital de relações sociais - acionou seu amigo Luiz Gabriel ${ }^{10}$ para que intercedesse em seu favor ${ }^{11}$. Luiz Gabriel, que era engenheiro agrônomo e tinha ligações empresariais com grupo agroindustrial catarinense Perdigão, ocupava nesse momento o cargo de Secretário da Agricultura de Santa Catarina. Ao que tudo indica, a ascensão de Luiz Gabriel ao cargo de Secretário da Agricultura teria sido o produto da ação de grupos empresariais catarinenses do setor agroindustrial no campo político visando a expansão de seu poder frente às decisões estatais (KLANOVICS, 2007). Assim, à luz de sociologia bourdieusiana poder-se-ia propor que a nomeação de Luiz Gabriel seria simultaneamente um produto e uma arma nas lutas pela obtenção das vantagens asseguradas pelas diferentes intervenções do Estado no campo econômico ou, o que dá no mesmo, nas lutas pelo poder sobre o poder do Estado (BOURDIEU, 2005).

Lançando mão das excelentes relações que desde o golpe de 1964 mantinha com os militares, Luiz Gabriel iniciou uma série de contatos com o então presidente do IBDF, o General Silvio Pinto da Luz, visando a inclusão da macieira na lei de incentivos fiscais. Desse modo, a inclusão foi finalmente obtida e a REFLOR pode iniciar, em 1969, a implementação dos primeiros 100 hectares de macieiras cultivadas com incentivos fiscais. Foi a partir desses primeiros grandes pomares cultivados com incentivos fiscais que a cultura da macieira espalhou-se, “[...] principalmente, nos Estados de Santa Catarina e Rio Grande do Sul, formandose [os] três [principais] polos de produção [no Brasil]: Fraiburgo, São Joaquim e Vacaria.” (PETRI et al., 2011, p. 50). Assim como o caso das centrais elétricas analisado por Granovetter \& MacGuire (1998) aqui igualmente a mobilização política de alguns agentes não só permite o sucesso do empreendimento como

\footnotetext{
${ }_{10}$ Devido à sua função de representante de muitas madeireiras catarinenses no Rio de Janeiro, Willy mantinha contatos constantes e continuados com os dirigentes do Instituto Nacional do Pinho (INP). Porém, com a transformação deste último em IBDF e sua transferência para a nova capital federal Brasília, Willy acabou perdendo seus antigos contatos. Nesse ponto, entrou em cena o amigo da família Frey, Luiz Gabriel, que devido a sua multiposicionalidade - empresário e secretário de agricultura estadual - e aos capitais dela decorrentes pode atuar como um legítimo broker. A partir do buraco estrutural gerado pelas alterações institucionais feitas pelo governo militar, ele estabeleceu uma ponte entre o campo econômico e o campo político-administrativo ao fazer com que a demanda de Willy Frey não apenas chegasse ao dirigente do IBDF, como ainda fosse devidamente acatada.

11 Sobre sua relação de amizade com a família Frey, Luiz Gabriel afirmou em entrevista concedida a Schmidt (1990, p. 73): "Eu me dava muito bem com o (René) Frey. Tinha contatos seguidamente com ele."
} 
reconfigura culturalmente o campo no sentido dado por Bourdieu, como veremos adiante.

\subsection{O Projeto de Fruticultura de Clima Temperado (PROFIT) em Santa Catarina}

A importância de Luiz Gabriel para a constituição da indústria brasileira de maçãs não se limitou, contudo, à sua contribuição para a inclusão da macieira na lei federal dos incentivos fiscais ao reflorestamento. Com efeito, como Secretário da Agricultura ele também apresentou o Programa Executivo Frutícola para Santa Catarina (PEDF), primeira tentativa estatal para o incentivo da fruticultura de clima temperado no âmbito estadual (KLANOVICS, 2007). O PEDF foi à base sobre a qual em 24 de dezembro de 1968 a Secretaria da Agricultura de Santa Catarina, ainda sob o comando de Luiz Gabriel, promulgou a Lei $n^{\circ} 4.263$ que criou o Projeto de Fruticultura de Clima Temperado (PROFIT) (SCHMIDT, 1990). Elaborado pelo engenheiro agrônomo e então presidente da Associação de Crédito e Assistência Rural de Santa Catarina (ACARESC), Glauco Olinger, o PROFIT surgiu com a finalidade de "[...] trazer uma alternativa econômica para as regiões Meio Oeste e Planalto Catarinense, que, à época, sofriam os efeitos da quase extinção do ciclo madeireiro, que fora importante." (SOUZA, 1996, p. 93). Contudo, dado o grande número de atividades econômicas que teriam possibilidades de ser desenvolvidas nessa região, pode-se perceber que a opção das autoridades estatais por investir na pomicultura não foi, de forma alguma, natural ou necessária. Como demonstra Schmidt (1990, p. 73), o próprio Luiz Gabriel “[...] destacava a importância que teve o "relatório" apresentado por Delbard, para sua tomada de decisão com relação à criação do Projeto de Fruticultura de Clima Temperado."

No âmbito das atividades que foram desenvolvidas pelo PROFIT durante seu período de existência estão incluídas não apenas pesquisas, treinamentos e ações de assistência técnica, mas também a oferta de financiamentos através de linhas de crédito específicas para a execução de projetos de fruticultura (SCHMIDT, 1990). De acordo com Schmidt (1990), somente entre 1970 e 1972 o PROFIT financiou entre 60 e $80 \%$ dos processos de instalação de 510 pomares de fruteiras de clima temperado (destaque para macieira) em Santa Catarina.

Nesse processo de estabelecimento de novos pomares financiados pelo PROFIT, quem mais uma vez se beneficiou significativamente foi a família Frey através de sua empresa SAFRA. Devido ao seu amplo pomar experimental de fruteiras de clima temperado, a SAFRA tornou-se uma das principais fornecedoras das mudas utilizadas na implantação dos pomares financiados pelo PROFIT. A 
participação da SAFRA nos mercados regional e nacional de mudas cresceu ainda mais a partir de 1969, quando o Ministério da Agricultura proibiu a importação de materiais genéticos (KLANOVICS \& NODARI, 2005). A partir desse momento a SAFRA começou a produzir em Fraiburgo suas próprias variedades de mudas (as quais, antes da nova lei, provinham sobretudo dos viveiros de Delbard na França) (KLANOVICS \& NODARI, 2005). Como demonstram dados de Brandt (2005), enquanto em 1969 a SAFRA comercializou apenas 35.186 mudas de macieira, em 1971 ela comercializou 262.810 mudas, o que corresponde a um crescimento de mais de sete vezes em apenas dois anos.

Em suma, o PROFIT teve grande importância para o desenvolvimento da pomicultura em Santa Catarina, haja vista que foi partir dele que o cultivo de macieiras, até o momento concentrado sobretudo na região de Fraiburgo, se espalhou para diversos outros municípios catarinenses (SCHMIDT, 1990; FREY, 2004; KLANOVICS, 2007).

\section{Considerações finais}

Lançando mão do instrumental fornecido pela Sociologia Econômica, nesse artigo buscamos analisar o processo de gênese da indústria brasileira de maçãs seguindo os passos da família Frey. Demonstramos que as atividades econômicas desenvolvidas pelos Frey contribuíram de forma determinante não apenas para a emergência do município de Fraiburgo (hoje considerado "berço da maçã brasileira"), mas também para a vinda dos empresários e técnicos franceses e franco-argelinos, os quais contribuíram para a gênese da indústria de maçãs tanto com capital econômico quanto com capitais social técnico-científico. Em associação com a famílias Evrard e Mahler, os Frey criaram a Sociedade Agrícola Fraiburgo Ltda. (SAFRA), grupo que realizou os experimentos que permitiram verificar que dentre as frutas clima temperado a maçã era a opção mais viável tecnicamente e rentável economicamente para a região de Fraiburgo. Contudo, como argumentamos, não obstante a grande importância do grupo SAFRA, foi apenas com a criação da empresa parceira REFLOR por Willy Frey que a indústria de maçãs de Fraiburgo realmente emergiu. Devido à sua trajetória sócio profissional particular - marcada, entre outras coisas, pela rigorosa disciplina familiar, a passagem num internato, a socialização precoce e continuada no mundo empresarial e a formação em áreas como contabilidade e administração -, Willy ocupou uma posição e constituiu disposições e capitais que lhe permitiram aproveitar a oportunidade em estado potencial aberta pela promulgação da lei de incentivos fiscais ao reflorestamento e convencer os demais atores do campo. 
Além disso, Willy foi igualmente hábil em construir e mobilizar uma rede de relações sociais que lhe permitiu obter - tanto diretamente, como por meio da ação de brokers (assim como Luiz Gabriel) - acesso a intervenções favoráveis do Estado (como a alteração na lei de incentivos fiscais) e recursos (como capital econômico) que se mostraram essenciais ao aproveitamento de tal oportunidade e, por conseguinte, à implantação de grandes pomares de macieiras em Fraiburgo pela sua empresa REFLOR. Longe da ideia do mercado espontâneo promovido por atores estratégicos, este artigo mostra a trajetória e tomada de posição de um agente que convence seus pares à produção de maçãs como parte do universo dos possíveis e contribui para identidade de produtora nacional deste cultivar em uma região, em particular.

\title{
Producing APPLES, BUILDING SENSES: GENESIS OF POMICULTURE IN SOUTHERN BRAZIL
}

\begin{abstract}
In the light of the Economic Sociology, in this article we analyze aspects of the genesis of the Brazilian apples industry in the footsteps of the Frey Family. We argue that the economic activities developed by the Frey contributed decisively not only to the emergence of the city of Fraiburgo (SC) but also to the development pf modern Brazilian pomiculture. Far from the idea of the spontaneous movement of the markets, we show how the position of an agente reconfigures the field by reconverting other agents and taking advantage of a window of opportunity of the law to encourage reforestation that becomes part of the universe of possibilities. We followed Willy Frey's social and professional trajectory by pointing out his ability to mobilize a network of relationships that allowed him to obtain - both directly and through broker's action - favorable State interventions and resources that were essential to the establishment of large orchards in Fraiburgo and, consequently, the conversion of the Southern region into the first e main pole producing apple in Brazil.
\end{abstract}

KEYWORDS: Brazilian apples industry; economic agents; position taken; State; market.

\section{REFERÊNCIAS}

ALDRICH, Howard E. Entrepeneurship. In: SMELSER, Neil J. \& SWEDBERG, Richard (Eds.). The handbook of economic sociology. New York: Russell Sage Foundation, 2005. 
BRASIL. Lei $\mathbf{n}^{\circ} \mathbf{5 . 1 0 6}$, de 2 de setembro de 1966. Dispõe sobre os incentivos fiscais concedidos a empreendimentos florestais. Disponível em: www.planalto.gov.br/ccivil_03/ leis/1950-1969/L5106.htm. Acesso em: 18 nov. 2016.

BOURDIEU, Pierre. Sobre o Estado: Cursos do Collège de France (1989-1992). São Paulo: Companhia das Letras, 2014.

. O campo econômico. Política \& Sociedade, vol. 1, n. 6, 2005.

As estruturas sociais da economia. Lisboa: Instituto Piaget, 2001.

BRANDT, Marlon. Uso comum e apropriação da terra em Fraiburgo-SC: do Contestado à Colonização. Dissertação de Mestrado em Geografia Universidade Federal de Santa Catarina, Florianópolis, SC, 2007.

. A criação da Sociedade Agrícola Fraiburgo (SAFRA) e o início da pomicultura em Fraiburgo/SC, na década de 1960. Revista Discente Expressões Geográficas, n. 1, jun. 2005.

BURKE, Thomas J. Fraiburgo: do machado ao computador. Curitiba: Gráfica Vicentina, 1994.

FLIGSTEIN, Neil. Mercado como política: uma abordagem político-cultural das instituições de mercado. Revista Contemporaneidade e Educação, ano VI, n. 9, $1^{\circ}$ semestre 2001.

FREY, Willy. Lá nos Frai. Curitiba: Sépia Editora e Gráfica Ltda., 2005.

. Fraiburgo: berço da maçã brasileira. Curitiba: Sépia Editora e Gráfica Ltda.,

2004.

. Reflorestar é a solução. Curitiba: Sépia Editora e Gráfica Ltda., 2003.

GRANOVETTER, Mark \& MCGUIRE, Patrick. The making of an industry: eletricity in the United States. In: CALLON, Michel (Ed.). Laws of the markets. Oxford: Blacwell, 1998.

GRÜN, Roberto. Dinheiro no bolso, carrão e loja no shopping: estratégias educacionais e estratégias de reprodução social em famílias de imigrantes armênios. In: ALMEIDA, Ana M. F. \& NOGUEIRA, Maria A. (Orgs.). A escolarização das elites: um panorama internacional da pesquisa. Petrópolis: Vozes, 2003.

KLANOVICS, Jó. Natureza corrigida: uma história ambiental dos pomares de macieira no sul do Brasil (1960-1990). Tese de Doutorado em História. Universidade Federal de Santa Catarina, Florianópolis, SC, 2007.

KLANOVICS, Jó \& NODARI, Eunice S. Das araucárias às macieiras: transformações da paisagem em Fraiburgo - Santa Catarina. Florianópolis: Editora Insular, 2005. 
KREUZ, Carlos L. et al. História e importância econômica da macieira. In: EMPASC. Manual da cultura da macieira. Florianópolis: EMPASC, 1986.

LAHIRE, Bernard. Homem plural: os determinantes da ação. Petrópolis: Editora Vozes, 2002.

MICELI, Sergio. Biografia e cooptação (o estado atual das fontes para a história social e política das elites no Brasil). In: Intelectuais à brasileira. São Paulo: Companhia das Letras, 2001.

NOGUEIRA, Maria A. Estratégias de escolarização em famílias de empresários. In: ALMEIDA, Ana M. F. \& NOGUEIRA, Maria A. (Orgs.). A escolarização das elites: um panorama internacional da pesquisa. Petrópolis: Vozes, 2003.

PETRI, José Luiz et al. Avanços na cultura da macieira no Brasil. Revista Brasileira de Fruticultura, volume especial, out. 2011.

RENK, Arlene. Etnicidade e itinerários de grupos étnicos no Sul do Brasil. In: Anais do XXII Encontro Anual da ANPOCS: Caxambu, 1998.

SCHMIDT, Wilson. O setor macieiro em Santa Catarina: formação e consolidação de um complexo agroindustrial. Dissertação de Mestrado em Desenvolvimento Agrícola. Universidade Federal Rural do Rio de Janeiro, Itaguaí, RJ, 1990.

SECCHI, Irineu. Homenagem de um colaborador no centenário de nascimento de René Carlos Frey. In: FREY, Willy. Lá nos Frai. Curitiba: Sépia Editora Ltda., 2005.

SILVA, Ary N. Trajetória de um empreendedor. Curitiba: Gigapress Gráfica e Editora Ltda., 2006SOUZA, Nelton R. O PROFIT. In: FURTADO FILHO, D.; SILVA, F. da C.; FRANCO, H.M. (Org.). Gotas de suor: uma trajetória de 40 anos. Florianópolis: EPAGRI, 1996.

WEBER, Max. Economia e sociedade: fundamentos da sociologia compreensiva. Volume II. Brasília: Editora da Universidade de Brasília, 2012.

Recebido em 10/08/2017.

Aprovado em 23/11/2017. 
